\title{
ISO 9001 Transition and its Impact on the Organizational Performance: Evidence from Service Industries of Pakistan
}

Waqar Ahmed

Department of Management Sciences, COMSATS Institute of Information Technology, Islamabad

\begin{abstract}
Purpose- The motivation behind this research work is to characterize and subjectively measure effectiveness of ISO 9001 as the accomplishment of the standard's targets and decide its effect on the dimensions of performance of service industries measured with operational performance and product/service quality.

Methodology/approach/design-A quantitative study was completed utilizing a sample of 300 ISO 9001ensured service industries. Data were collected from the quality experts, process architects, software engineers and project managers of the organizations through an organized questionnaire. The gathered information was then analyzed utilizing descriptive statistics. Inferential statistics, Regression was likewise utilized in testing the impact of ISO 9001 accreditation on performance of an organization. Exploratory Factor analysis and confirmatory factor analysis were employed. Analysis was done utilizing SPSS 21, statistical package, by encoding replies from the questionnaires. To determine the effectiveness of ISO 9001 and its impact on the performance dimensions of service companies multiple linear regression analyses was run.
\end{abstract}

Findings- The outcomes of the present study affirm the dimensionality of the ISO 9001 viability (assessed by the level of accomplishment of the standard's destinations, in particular risk identification,continuous improvement, prevention ofnonconformities, and customer satisfaction) and uncover its huge commitment to influence the service industries/organization performance. The operationalperformance and product/service quality of the service industries are specifically and essentially impacted by effectiveness of ISO 9001.

Research implications/Limitations - The study aimed to evaluate the effectiveness of ISO 9001 organizational performance by assessing whether ISO certification can make a positive impact on operational performance and product / service quality. Finally, this study was directed to only Software industries of Pakistan, future researcher may conduct this research in any other sector of Pakistan like manufacturing, retailing etc. Current research work focused private and government software industries of Pakistan, future researcher may compare the ISO effectiveness on organizational performance in developed and developing countries.

Practical Implications-By characterizing ISO 9001 adequacy in light of its goals, process architects and top managers might know about what to enhance to expand the standard's viability and along these lines specifically enhance performance of Service Company as far as quality and operative results and in a roundabout way as far as financial results.

Originality/value -Grounded on the center issues of effectiveness of ISO 9001 this empirical study affirms its multi-dimensional structure and decides the commitment of ISO 9001 adequacy to particular service industries performance dimensions.

Keywords: Pakistan, product/service quality, organizational performance, risk based thinking, ISO 9001 effectiveness, and Service industries.

\section{INTRODUCTION}

The series of standard ISO 9001 quality system was created in 1987 by the International Organization for Standardization (ISO), which means to give direction on quality systems for organizations and enhance their performance with a specific end goal to give and more solid quality items and well support of their clients. Beattie (1999) and Evangelos (2013) shows that certified companies have received ISO 9001 implementation, including internal and external benefits. ISO 9001 series certification has become essential for the software industries who want to enter the international market, especially small and medium industries. ISO survey (2007) further describes that when the organization is ISO, there are a number of benefits that include efficient operations, customer satisfaction, improved financial performance, satisfaction of stakeholders, sustainability, continuous improvement, international recognition, improving the quality and image. (Terlaak \& King, 2006) 
Waqar Ahmed "ISO 9001 transition and its impact on the organizational performance: Evidence from Service Industries of Pakistan"

observed that certified institutions develop faster after certification, operational improvements and does not account for this growth. They conclude that this advantage does not result from changes in the quality of performance, inventory management, allocation of production companies, or differences in growth pre-certification.

The motivation behind this research is to recognize and group potential advantages and confirm the usage of value quality management system (QMS) as per ISO 9001:2015.In addition to determining the performance of certification ISO 9001 performance the operator of the personal performance and the performance of the market in Pakistan. This study also attempts to determine the company's approach to marketing moderate the relationship between ISO 9001 certification and marketing performance. Differences also assesses the perceived barriers to ISO 9001 implementation between 9001 and ISO certified company. This applied to current research as the study was to compare the performance before and after certification to establish the impact of ISO 9001 certification on performance. Multiple linear regression analysis was also used to determine the impact of ISO 9001 on the effectiveness of the performance of the service companies.

Considering the background, the purpose of study is to determine the ISO 9001 effectiveness on organizational performance as there is a growing trend in many industrialized countries, which requires departments, statutory bodies and other public sector organizations to be modified to be more efficient and thin, and eventually financially more prudent in their operations. While some organizations have gone through the complete privatization process, others for whom it was not a realistic option, however, responded by trying to mimic the philosophies and discipline of private sector organizations. This included the selection of thoughts, practices, programs, frameworks, comparative instruments and other interventions of management utilized as a part of private area associations. ISO 9001 quality management is one of the tools. This led researchers to study how the adoption of ISO 9001 impact on the performance of the research service agencies indicates that the company is certified ISO 9001 implementation including internal and external benefits. Internal benefits are defined as internal functions such as organizational structure and process organization. External benefits are the advantages related to the organization from its environment, including the outsourcing of resources, software consultancy, tender the project and financial performance. ISO 9001 series has become essential for organizations that want to enter the international market, especially small and medium industries. This happened in part because their large corporate customers that still requires its suppliers or subcontractors to be certified. In addition, some countries or economic organizations impose the rules of the ISO 9001 series to enter their market. In addition, the competitive pressure occurs in an area where the company uses the ISO series certification for marketing purposes in 9001 and it forces others to follow in order not to be charged at a competitive disadvantage. ISO 9001 is a series of standards for quality management system that can be used for external quality assurance purposes. It establishes standards for the systems and documentation (not product) is to provide organizations with guidelines on how to implement the system of revenue management and quality systems. Registration policy proves to customers that the organization of the delivery has reached a basic level of quality assurance through formal and documenting its quality management system. Although the initial impetus for the development of standards comes from the energy industry, defence equipment and telecommunications, followed by its main users are small to medium manufacturing organization. As a result, most of the accumulated knowledge of ISO 9001 is informed by the experience of manufacturing.

ISO 9001: 2015 requirements standard quality management system has been published and distributed on September 23, 2015. The last major revision of the standard was completed in 2000. It has been fifteen years a revision of the standard was made and much has changed in our global business community. Revised standard reflects key changes which include:

- Put more emphasis on developing a management system tailored to the specific needs of each organization and strategic direction

- Improved management reporting requirements and superior alignment with the goals and business strategy

- Requirements based on thought and documented risk, making the system a management system for the prevention of continuous improvement 
Waqar Ahmed "ISO 9001 transition and its impact on the organizational performance: Evidence from Service Industries of Pakistan"

- Line with multiple criteria by using a common basic structure and text

- Provide a solid base of all the needs for the next 10 years or more

- Stay generic and relevant for all sizes and types of organizations in all sectors

- Keep the current focus on the effective management of the process to produce the desired results

- Consider changes in practices and quality management system technology since the last major revision in 2000

- Reflect changes in the environment increasingly complex, dynamic and demanding organizations operate.

- To facilitate the effective implementation of the organization and evaluation of effective compliance for first, second and third

- Use the language and writing style simplified to facilitate the understanding and uniform interpretation of its requirements

Finally, the study will contribute to greater and wider scope of business and university research in terms of the impact of ISO certification on organizational performance. Future researchers will not just use the study as a reference shape, but also conduct research into other areas proposed research study.

The approach to the investigation work is a sequential process. It includes:

1. Going through qualitative analysis, which includes the exploration of the transition from ISO 9001: 2008 to ISO 9001: 2015 with main focus on Risk based thinking and the impact of the ISO 9001: 2015on the effectiveness of the performance of the organization through a review of the literature and also included open-ended qualitative interviews to validate the results.

2. The hybrid form of a quantitative analysis, which included an online survey closed for validation of both findings and motivation of the importance of this research.

Outlining the first run through in the service industries of Pakistan ISO 9001 transition and ISO viability as the accomplishment of ISO 9001 goals, the motivation behind the present review is twofold: first is to affirm, by giving exact confirmation from the service sector, the multidimensional structure of ISO 9001 adequacy. Second to that is to highlight the effect of ISO 9001 viability on the performance of service industries (characterized as product/service quality and operational performance). By investigating ISO 9001 adequacy examples and execution results in service industries, this review gives new and for all intents and purposes applicable bits of knowledge into the writing. Information from small and medium size organizations from the service industries with the utilization of exploratory factor analysis (EFA) and Confirmatory factor analysis (CFA) recognize and bolster the presented hypotheses.

Whatever remains of the paper is organized as takes after: in the initial section, the literature is reviewed on keeping in mind the end goal to correctly characterize ISO 9001 viability and particular organization performance dimensions. At that point, the hypothesis of present study are defined. In the following part, the approach of the research study is depicted which is trailed by the analysis of data and the particular results. In the last part the research design, methodology and the results of the study will showcase and analyzed. Finally, the discussion, interpretation, conclusions, limitations and recommendations of the study for future research are presented.

\section{LITERATURE REVIEW}

\section{Effectiveness of ISO 9001}

The intension of ISO (International Organization for Standardization) is not only to prepare/create performance standards, however also to define the procedure by which standards of quality management can be completed, and for which the efficiency and effectiveness of QMS could improve (Walker \& Johnson, 2009). As per standards of ISO 9001, the "efficiency" can be explain as the degree to which intentional goals have been attained (ISO 9001: 2000, 2000). Van der Spiegel et al. (2007) show that, in order to assess the extent to which predetermined objectives have been fulfilled should test efficiency of ISO 9001. ISO 9001 (ISO 9001: 2008, 2008) and ISO (2008) the purpose of 
Waqar Ahmed "ISO 9001 transition and its impact on the organizational performance: Evidence from Service Industries of Pakistan"

the standard stands: the prevention of non-compliance with the focus on continuous improvement and customer satisfaction. These goals are especially dependent not only standard, but also many of the researchers and experts from across the world (van der Spiegel et al, 2004; Heras et al, 2006; \& Gotzamani et al, 2007). Psomas et al. (2013) delivers an empirical evidence to provision this consent on the basic structure of ISO 9001 performance. In particular, the use of a sample of small and medium-sized enterprises in the service (SMEs), they confirm the ISO 9001 three goals from the literature (non-compliance preventions, customer satisfaction, and lastly continuous improvement) that defines the efficiency of ISO 9001. Indicators to assess these goals are imitative from the survey Psomas (2013).

\section{Company Performance}

To measure performance via stringent may have a negative impression on the enduring feasibility of an organization, so a wide range of performance measures need to develop by an organizations (O'Mara et al., 1998). Scholar Lee et al. (2009) examined the performance of an ISO 9001 certified organization by components like satisfaction of customer with the quality of service, effectiveness of internal management, the poor quality cost and the number of personal business.

The study was done McAdam and Canning (2001) demonstrates the benefits of ISO 9001 for small professional service firms, which are related to the internal management system and communication, quality of service and profit margins. Mansur Nahra and Singh (2006) investigated the effectiveness of the work and the financial institutions of the public sector due to the implementation of the ISO 9001 standard Singh et al. (2006) examine whether the quality of customer service, documentation process, the number of errors and defects and the amount of business and the implementation of ISO 9001 by Augustyn (2000), to assess the potential impact of ISO 9001 implementation of the performance of small tourism businesses appeal to customers the quality of service, re-work, efficiency, error rate, productivity, control costs and sales volume, (Tang\& Kam ,1999) study the consulting firm to study the benefits of ISO 9001 implementation, such as those relating to internal trade, image quality and value of the company.

The study of (Prajogo \& Brown, 2006) demonstrate skills and the results of the organization's performance (quality), ISO 9001 Non-manufacturing companies. Do the above analysis in mind the two dimensions of performance were selected for this study: operational performance and product/ service quality.

Indicators/variables to analyze product/services quality are obtained keeping study of (Karapetrovic \& Willborn ,1998), (McAdam \& Canning , 2001), (Prajogo \& Brown ,2006), Dick et al. (2002), Singh et al. (2006), Su et al. (2008), Zaramdini (2007), Lam et al. (2012) and (Vazquez-Bustelo \&Avella ,2010). Indicators/variables to analyze operational performance are obtained keeping study of (Pheby \&Augustyn, 2000), (Karapetrovic \& Willborn, 1998), (Canning \& McAdam, 2001), Zaramdini (2007), Salaheldin (2009), Singh et al. (2006), and Lee et al. (2009).

\section{Measuring Instrument Development of ISO 9001 Transition and Effectiveness}

ISO 9001 introduced in 1987, the ISO 9001 series of standards has been a worldwide success, and these standards are now considered as minimum requirements for a quality management system. List of ISO 9001 certified companies are increasing day by day in every year. In the literature the advantages of ISO 9001 certification can be divided into two categories: business benefits and operational benefits. Operational benefits are related to the internal organization of the work, such as productivity and quality, while the commercial advantages of financing and marketing in Indonesia, SGS (2001) found that the certification is done .The belief that it will bring external benefits such as improved productivity and operational efficiency, greater leadership and increased staff awareness.

(Wayang, Kirche \& Khawla, 2002), points out that many empirical studies have been conducted to ISO certification, but unfortunately it leaves many questions important research about ISO 9001 high above all unexplored certification i.e. if the ISO 9001 certification provides certified companies with a competitive edge over non-certified businesses, as evidenced by the superior performance of the organization.

ISO 9001 standard is widely used standards of quality management by many organizations around the world as it's proved from literatures available. ISO 9001 sparked different perceptions especially on the resulting benefits for certified organizations. It is not clear whether the certification actually lead 
Waqar Ahmed "ISO 9001 transition and its impact on the organizational performance: Evidence from Service Industries of Pakistan"

to improved financial performance or vice versa. Various operational and quality measures are used in various studies from the observations to investigate the effect of ISO 9001 certification in organization performance that causes different results.

The present study examined the gap in the literature by ISO 9001 certification ISO determine whether in fact the result of the higher performance of the organization especially in the Pakistan IT industry.

ISO 9001 will have real advantages for the arrangement of value administration (QMS) with less accentuation on documentation and new methodologies/fortified as the examination of the association and the setting of partners (applicable), Risk management and based thinking information and ought to be a stage towards TQM. A key change is that associations should be clearer about what they say they will give and the principle inquiry is the way for the ISO/TC 176 can abandon estranging the "conventional" clients.

As indicated by the ISO beneath are the primary changes in phrasing somewhere around 9001:2008 and draft DIS 9001: 2015/ISO (source: TC 176/SC 2/WG 24/N 112/ISO, 2014):

- Products for items and administrations.

- Exceptions out of date.

- Documented records are reported change data.

- The climate of the work environment for the operation of the procedure.

- Products obtained happening outside gave items and administrations.

- Suppliers are presently outside suppliers.

There will be the ideal opportunity for clients to make the important changes in accordance with their quality administration framework - a three-year move period concurred with CASCO/ISO and the IAF, after the production of the another version form in which is ISO 9001: 2008 accreditation keeps on being perceived.

The study is directed by the following intents;

i. To examine the effectiveness of ISO 9001 (prevention of nonconformities (PNC), customer satisfaction (CS), risk identification (RI) and continuous improvement (CI))on operational performance

ii. To investigate the effectiveness of ISO 9001 (prevention of nonconformities (PNC), customer satisfaction (CS), risk identification (RI) and continuous improvement (CI)) on product/service Quality.

\section{Continuous Improvement}

The process of continuous improvement, is often designated as the continuous improvement of the process, is a continuing effort to improve their products, services or processes. According to Psomas et al. (2013), these efforts can be better to pursue "incremental" over time or refining "breakthrough" at a period.

\section{Customer Satisfaction}

Customer satisfaction is a marketing term that measures how the product or service provided by a company meet or exceed expectations of a customer. Customer satisfaction is important because it gives traders and owners of businesses with a metric that can be used to manage and improve their businesses (Psomas et al. 2013).

\section{Risk Identification}

According to L.M. Fonseca (2015), risk identification is the initial step in pre-emptive risk management practise. It offers opportunities, indicators and information that allows an organization to raise major risks prior they may negatively distress operations and consequently the firm.

\section{Prevention of Nonconformities}

According to Psomas et al. (2013), the actions related to non-conformities in products, services and results of the audit. Any remedial action engaged to exclude the reasons of actual nonconformities 
Waqar Ahmed "ISO 9001 transition and its impact on the organizational performance: Evidence from Service Industries of Pakistan"

will stay appropriate towards the scale of the problem while being proportionate to the risks presented by the non -conformity. The root cause of nonconformity in products and services, as well as the investigation process defect management system and measures to prevent their recurrence implemented.

\section{Organizational Performance}

According to Psomas et al. (2013), the impact of ISO 9001 effectiveness on the organizational performance (defined as product/service quality and operational performance). Researcher explored the ISO 9001 effectiveness patterns and performance outcomes in service organizations, this study provides new and practically relevant insights into the literature.

\section{Operational Performance}

According to Psomas et al. (2013), the measured performance of the company in respect of the standards or indicators of performance, efficiency and environmental responsibility, cycle time, productivity, waste reduction, and regulatory compliance.

\section{Product / Service Quality}

According to Psomas et al. (2013), product and services that come across or surpass customer anticipations results in customer satisfaction. Quality is the product/service performed waited. Before a customer makes a (currency exchanges for a product/service) purchase he had a mental calculation.

\section{Development of Hypothesis}

In light of the disagreements exhibited before in the initial section on the significance of ISO 9001 accreditation for execution or more writing audit, the motivation behind the present study are in accordance with proposals of numerous analysts' for further research is to ask for and analyze the effect of ISO 9001 effectiveness on performance of an organization.

1. H1a: There is a significant relationship between Continuous improvement (CI) and operational performance

2. H1b: There is a significant relationship between Prevention of nonconformities (PC) and operational performance

3. H1c: There is a significant relationship between Customer satisfaction (CS) and operational performance

4. H1d: There is a significant relationship between Risk based thinking/assessment (RI) and operational performance

5. H2a: There is a significant relationship between Continuous improvement (CI) and product/service quality

6. H2b: There is a significant relationship between Prevention of nonconformities (PC) and product/service quality

7. H2c: There is a significant relationship between Customer satisfaction (CS) and product/service quality

8. H2d: There is a significant relationship between Risk based thinking/assessment (RI) and product/service quality

\section{RESEARCH METHODOLOGY AND DESIGN}

\section{Research Design}

A formal descriptive, cross-sectional and statistical research design is utilized in the present study. This design is chosen since randomization in selection of employees is not advantageous and fitting for the study. The design is descriptive in light of the fact that the principle point of the study is to uncover the relationship among variables i.e. product/service quality and operational performance as the independent variables and prevention of nonconformities, customer satisfaction, risk identification and continuous improvement as dependent variables. In term of ISO 9001 effectiveness, the design of the research can likewise be sorted into cross sectional and longitudinal (Babbi'e, 1986; Neuman, 
Waqar Ahmed "ISO 9001 transition and its impact on the organizational performance: Evidence from Service Industries of Pakistan"

2003).The fundamental qualities of a cross-sectional design are that all information of variables is gathered only once at a solitary point in time (Bryman, 2004). Unexpectedly, a longitudinal design includes gathering information from the same respondents over a time frame to observe the directions and changes in their responses over time (Shaughnessy \& Zechnmeister, 1994: Zikmund, 1997).

Cross sectional design is viewed as being moderately low in expense and time since it just takes a depiction of an ongoing phenomenon (Hussey and Hussey, 1997). This reason among, different things, underline the decision of cross sectional and statistical design for this research.

A lack of assurance in respect of assessing to the same respondents for a possible follower research was another reason not to select a longitudinal design.

\section{Data Collection Instrument}

Refers to the use of tools for collecting data and how these tools have been developed. The data collection instrument used to collect data from selected respondents was questionnaires. The decision of tool is guided by the way of the information to be gathered, the time accessible and the goals of the study.

\section{Development of Questionnaires}

A study was led in Pakistan ISO 9001 guaranteed programming organization by the examination presumptions above are tried. Information were gathered utilizing an organized survey. This concentrate mostly embraces the measure from the investigation of Psomas et al. (2013) to evaluate ISO 9001 compelling of sustenance assembling organizations. This instrument depends on ISO 9001 determined reason (avoiding non-conformities, improving customer satisfaction and continued improvement) and their pointers as they have been distinguished in the writing. Be that as it may, the survey things are altered by qualities of a service industries alongside the addition of risk based thinking and its measures. Point to the size of the performance of services relating to the quality of the product / service and operational performance of business added in the survey. Scholastics and experts in quality management domain inspected the primary rendition of the survey to decide fruitful adjustment. Taking into account their proposals, question wording has been enhanced to make it more finish. What's more, a pilot study was led utilizing sample size of five IT industries already implemented QMS.

The pilot study affirmed the pertinence of the survey things for IT/software organization. The polished form of the survey comprises of three sections. The initial segment incorporates questions about the demographics of an organization. Section II is aninadequate and ISO 9001 contain explanations on markers of ISO 9001 objectives. Finally last section of survey contains articulations about the extent of execution identified with Product/service quality and operational performance. Researcher solicited respondents to demonstrate their level from assertion or conflict with these announcements, utilizing a seven point Likert scale, 7 being "Strongly agree" and 1 spoke to "Strongly disagree".

\section{Procedure of Sampling and Sample Selection}

300 respondents were chosen as sample size utilizing purposive sampling for officials, both substantiated and stratified inspecting and basic irregular testing place for the working level; staff chiefs in various portions of the administration area of Lahore. Respondents were chosen on the comfort testing plan. Accommodation inspecting was utilized as a part of exploration where the specialist is occupied with getting a modest approach to guarantee an adequate number of studies Black (1999) and about the realities (McDaniel \& Gates, 1991).

Employees were requested that rate taking into account the view of the effect of the preparation gave by their current authoritative responsibility hierarchical aptitudes, upkeep and execution.

The way of work is delegated contractual or permanent .Sample size was calculated using below mentioned equation.

$$
\text { Sample Size }=\frac{\frac{z^{2} \times p(1-p)}{e^{2}}}{1+\left(\frac{z^{2} \times p(1-p)}{e^{2} N}\right)}
$$

Where $\mathrm{N}=$ Population size 
Waqar Ahmed "ISO 9001 transition and its impact on the organizational performance: Evidence from Service Industries of Pakistan"

$\mathrm{e}=$ Margin of error (e is percentage, put in decimal form e.g. $3 \%=0.03$ )

$\mathrm{Z}-$ Score $=\mathrm{Z}$

Here $\mathrm{N}=400$

$\mathrm{e}=3 \%$

$\mathrm{Z}=95 \%=1.96$

The z-score is the number of standard deviations a given proportion is away from the mean.

\section{Data Analysis Techniques}

Data analysis is the process of creating order, structure and definition of the mass of information collected Mugenda (2003). The data collected were analyzed using descriptive statistics. Descriptive statistics quantitatively describes the main features of the discipline of collecting data, providing simple summary of the sample and the comments made by Dodge (2003). Descriptive statistics were used together with frequency tables and percentages. Graphs and tables are also used to analyze the data. Another descriptive statistics is that correlation is used to determine the relationships between variables of the study. ANOVA inferential statistics are also used to test the research hypotheses. It is used to measure the relative influence of the independent variable on the basis of its covariance dependent variable and was useful in forecasting. Usually, it is more appropriate when both independent and dependent variable is the interval, although some social scientists are also using ordinal data. To establish the relationship between the variables, the study used correlation analysis and ANOVA model. Correlation analysis established the relationship between the dependent variable while to establish an association between the dependent and independent variables, analysis of variances or regression was used. Analysis was performed using SPSS statistical package through a computerized response coding questionnaires and interview guides. Presentation of this information is made using tables.

\section{Inferential and Descriptive Analyzes}

Researcher used SPSS version 21.0 for data analysis. In SPSS data/information from questionnaires entered in spread sheet later it was encoded and edited to do examination/analysis. To accomplish this specific goals of the research, the study sample was made to the attributes of the independent and dependent variables at last hypotheses was developed through the use of different statistical methods, including

- Reliability Tests

- Descriptive Statistics

- Correlation Analysis

- Confirmatory factor analysis (CFA)

- Exploratory factor analysis (EFA)

\section{ANALYSIS OF DATA AND RESULTS}

\section{Respondents Profile}

This research is centered on the business of IT administrations and software house. This layouts the examination's unit of investigation among representatives of software house, and IT businesses. The objective populace was characterized as complete gatherings of particular components pertinent populace for the examination bunch. The objective populace of this examination incorporates workers of administration associations working in Pakistan. The explanation behind picking the administrations area is to inspect the relationship between customer satisfactions (CS), Risk identification (RI), prevention of nonconformities (PNC), continuous improvement (CI) on organizational performance and product/service quality. There is an absence of examination identified with the CS, RI, PNC, CI and the result variables in service sector. The division gives administrations to its customers keeping in mind the end goal to pull in the business sector and addition piece of the overall industry. To pick up an upper hand and catch market, administration associations instruct their workers on ISO 9001 and teach their representatives to give benefits productively and professionally. This is the reason the service industries are considered as most appropriate spot to study. 
Waqar Ahmed "ISO 9001 transition and its impact on the organizational performance: Evidence from Service Industries of Pakistan"

\section{Reliability Issues Analysis}

Alpha coefficients were calculated to determine and judge the internal consistency levels adopted, including continuous improvement, prevention of non-conformities, customer satisfaction, risk identification, operational performance and the service / product quality. All the dependability of assessments for the variables incorporated into the study exhibited at the following table.

Table4.1.11. Cronbach's Alpha of composite Scales $(N=300)$

\begin{tabular}{|l|l|l|}
\hline Variables & No. of items & Cronbach's Alpha \\
\hline CI: Continuous improvement & 7 & 0.894 \\
\hline PNC: Prevention of nonconformities & 6 & 0.872 \\
\hline CS: Customer Satisfaction & 6 & 0.867 \\
\hline RI: Risk identification & 4 & 0.870 \\
\hline OP: Operational performance & 3 & 0.965 \\
\hline PQ: Product/service Quality & 3 & 0.841 \\
\hline
\end{tabular}

The consistency of latent factors are affirmed, by Hair et al. (2005), by Cronbach (Table 4.2.1). All coefficients demonstrate adequate to great trustworthiness. Build legitimacy of the latent factors were affirmed, by Hair et al.(2005), convergent validity analysis. The face legitimacy content (questionnaires/poll was created in light of a broad writing survey, a pilot research and assessment of the university) and nomological legitimacy (critical associations among the latent factors)

The table 4.1.1 above shows Alpha trustworthiness coefficients of the considerable number of variables. The estimations of trustworthiness coefficients of all scales are fair and adequate extent. The most extreme measures of coefficient reliability is for Risk identification $(0.870)$ and operational performance (0.965), whereas product/service quality has minimum reliability of coefficient $(0.841)$. The results are comparable to, and in accordance with published estimates of the current level.

\section{Exploratory Factor Analysis (EFA) of ISO 9001:2015 Objectives}

Anderson (1988) described different basic guidelines for the reliability and validity of measurement scale used in the study. A step-by-step approach is used for analysis. First of all, it's necessary to perform factor analysis as data reduction techniques in order to diminish the questions in the measurement tool. For the purpose of examining the common variance, all the items were included in the analysis. KMO and Bartlett test was incorporated for checking the appropriateness of scale used in this study and prove about adequacy of sample. Table 4.2.1 shows the results for KMO and Bartlett test. The value of KMO is 0.781 which shows more than the appropriateness according to the standard criteria of KMO value 0.50 so KMO value is above average. Bartlett Test is also showing the significant value 0.000 which makes this analysis perfect for performing factor analysis. Secondly according to the recommendation of (Hair, Tatham, Anderson, \& Black, 2006), Varimax rotation should be used in the rotation of each factor in the factor loading and set criteria of cut-off value is 0.50 in exploratory factor analysis. All the values were above the set criteria of cut-off value.

Table4.2. 1EFA of ISO 9001:2015 objectives

\begin{tabular}{|c|c|c|c|c|c|c|}
\hline \multirow[t]{2}{*}{ Measured Variables } & \multicolumn{6}{|c|}{ Components } \\
\hline & $\begin{array}{l}\text { Continu } \\
\text { ous } \\
\text { improve } \\
\text { ment }\end{array}$ & $\begin{array}{l}\text { Preventio } \\
\text { n of } \\
\text { nonconfo } \\
\text { rmities }\end{array}$ & $\begin{array}{l}\text { Custom } \\
\text { er } \\
\text { Satisfact } \\
\text { ion }\end{array}$ & $\begin{array}{l}\text { Risk based } \\
\text { Thinking/ } \\
\text { Assessment }\end{array}$ & $\begin{array}{l}\text { Operat } \\
\text { ional } \\
\text { Perfor } \\
\text { mance }\end{array}$ & $\begin{array}{l}\text { Product } \\
\text { /Service } \\
\text { Quality }\end{array}$ \\
\hline $\begin{array}{l}\text { Does successful marketable } \\
\text { strategy for constant quality } \\
\text { change has been produced? }\end{array}$ & .971 & & & & & \\
\hline $\begin{array}{l}\text { Does an authoritative structure } \\
\text { (e.g. quality } \\
\text { Board of trustees and circles) } \\
\text { has been produced to bolster } \\
\text { the change of the QMS? }\end{array}$ & .891 & & & & & \\
\hline $\begin{array}{l}\text { Has the procedures, methods } \\
\text { and items/administrations are } \\
\text { persistently checked, evaluated } \\
\text { and progressed? }\end{array}$ & .901 & & & & & \\
\hline
\end{tabular}


Waqar Ahmed "ISO 9001 transition and its impact on the organizational performance: Evidence from Service Industries of Pakistan"

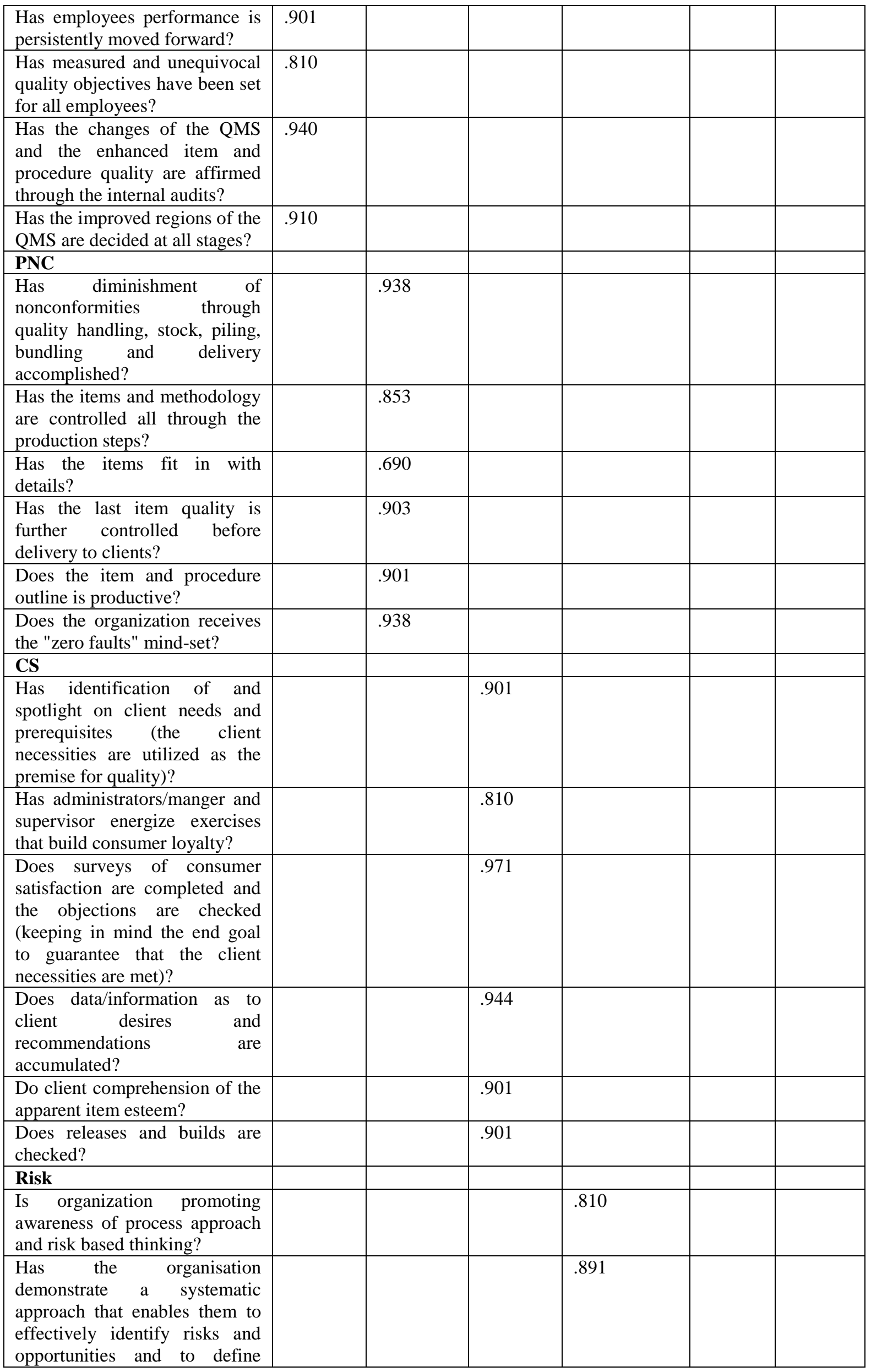


Waqar Ahmed "ISO 9001 transition and its impact on the organizational performance: Evidence from Service Industries of Pakistan"

\begin{tabular}{|c|c|c|c|c|}
\hline $\begin{array}{l}\text { actions as input to the planning } \\
\text { of their QMS? }\end{array}$ & & & & \\
\hline $\begin{array}{l}\text { Has the association considered } \\
\text { the inner and outside issues and } \\
\text { the prerequisites of the invested } \\
\text { individuals while deciding the } \\
\text { risks and opportunities? }\end{array}$ & & .944 & & \\
\hline $\begin{array}{l}\text { Has the organization integrated } \\
\text { and implemented the actions } \\
\text { for risks and opportunities into } \\
\text { its quality management system } \\
\text { processes? }\end{array}$ & & .938 & & \\
\hline $\begin{array}{l}\text { Has company efficiency is } \\
\text { improved by opting ISO } 9001 \text { ? }\end{array}$ & & & .938 & \\
\hline $\begin{array}{l}\text { Has company productivity is } \\
\text { improved by opting ISO } 9001 \text { ? }\end{array}$ & & & .810 & \\
\hline $\begin{array}{l}\text { Has company processes } \\
\text { effectiveness been improved by } \\
\text { opting ISO 9001? }\end{array}$ & & & .944 & \\
\hline $\begin{array}{l}\text { Has products and services been } \\
\text { improved by opting ISO } 9001 ?\end{array}$ & & & & .940 \\
\hline $\begin{array}{l}\text { Has consistent and reliable } \\
\text { product/services been delivered } \\
\text { by opting ISO } 9001 \text { ? }\end{array}$ & & & & .971 \\
\hline $\begin{array}{l}\text { Has product/service } \\
\text { conformance to specification by } \\
\text { opting ISO 9001? }\end{array}$ & & & & .938 \\
\hline \multicolumn{5}{|c|}{$\begin{array}{l}\text { Extraction Method: Principal Component Analysis. } \\
\text { Rotation Method: Varimax with Kaiser Normalization. }\end{array}$} \\
\hline
\end{tabular}

The first construct is continuous improvement (CI) that is having 7 factors and these factors are loading heavily on column 1 . Furthermore the value of all factors is beyond the cutoff value of 0.5 so it means all the factors are tapping the construct of continuous improvement in a decent way. Next to continuous improvement, there is loading for construct prevention of nonconformities (PC), as it is obvious from the table of exploratory factor analysis (EFA) there are six factors for PC and these factors are loaded in column 2 and all the values of these loadings are above the average value of 0.5 so these results provide sufficient ground that the six factors of prevention of nonconformities (PC) are tapping the construct of PC properly. Next we have the construct of customer satisfaction that is indicated by CS in EFA table 4.2.1, it is having six factors and these factors are being loaded in column three, all the loadings in this column are greater than 0.5 so there is no issue for factor scores of customer satisfaction.

After customer satisfaction, there are loadings for Risk based thinking (RI) in fourth column and there are four factors tapping the construct of RI in this column. All the loadings are good enough to confirm that there is no problem in factor loadings for risk based thinking. Fifth column belongs to construct operational performance mentioned by OP in EFA table 4.2.1. It is having three factors and all factor scores are beyond the level of 0.5 threshold so results of factors are satisfactory. Finally, we have our last construct Product/service quality mentioned by PQ and it is in sixth column. There are three factors for product and service quality and loadings are very good for tapping the construct of product and service quality. So all these results of EFA pave our way for CFA in a decent manner.

\section{Assessment of Overall Fitness of Measurement Model}

Table 4.4.1 illustrates the model fit's overview. In model fit, the value of X2 is 470.3 the value of degree of freedom is 267 and P- value is .000 . The term NPAR represents the parameters' number. CMIN $\left(\mathbf{X}^{2}\right)$ is a measure which is used in order to typify the variation among covariance matrix of unrestricted sample and covariance matrix of restricted sample. DF is the symbol of degree of freedom and $\mathrm{P}$ represents the probability value. 
Waqar Ahmed "ISO 9001 transition and its impact on the organizational performance: Evidence from Service Industries of Pakistan"

Table4.4.1. Model Fitness

\begin{tabular}{|l|l|l|l|l|l|}
\hline \multicolumn{1}{|c|}{ Model } & NPAR & $\mathbf{X}^{2}$ & $\mathbf{D F}$ & $\mathbf{P}$ & $\mathbf{X}^{2} / \mathbf{D F}$ \\
\hline Default Model & 69 & 470.311 & 267 & .000 & 1.761 \\
\hline Saturated Model & 325 & .000 & 0 & & \\
\hline Independence Model & 25 & 2343.239 & 300 & .000 & 7.811 \\
\hline
\end{tabular}

In SEM, the small value of chi- square is the indication of the testing of theoretical model. As $\mathrm{X}^{2}$ in this model is small with the value of 470.311 so this value is considered good.

One of the metric that is suggested better for fit is X2/Df (Bentler, P. M. \& Bonett, 1980). In the measurement model of this study, the value of $\mathrm{X} 2 / \mathrm{DF}$ is $1.7(\mathrm{x} 2=470.311$; $\mathrm{DF}=267)$. This value is the indication of the fact that model fit is acceptable.

Table4.3.2. Statistic of Goodness of Fit of measurement Model

\begin{tabular}{|c|c|c|}
\hline Fit Statistic & Acceptable Range & Obtained Value \\
\hline $\mathbf{X}^{\mathbf{2}}$ & - & 70.311 \\
\hline Df & - & 267 \\
\hline $\mathbf{X}^{\mathbf{2}}$ Significance & $\mathrm{p}<=0.05$ & 0.000 \\
\hline $\mathbf{X}^{\mathbf{2}} / \mathbf{D f}$ & $<3.0$ & 1.761 \\
\hline GFI & $>0.90$ & 0.912 \\
\hline AGFI & $>0.90$ & 0.901 \\
\hline NFI & $>0.90$ & 0.932 \\
\hline CFI & $>0.90$ & 0.935 \\
\hline TLI & $>0.90$ & 0.925 \\
\hline RMSEA & $<0.05$ & 0.040 \\
\hline RMR & $<0.05$ & 0.048 \\
\hline
\end{tabular}

Table 4.3.2 illustrates the other dissimilar measures which are necessary to access the goodness of fit of model. The expected range of GFI is $>0.90$. In this measurement model the obtained value of GFI is 0.912 and it is above the recommended level. The fit statistics of AGFI has expected range of $>$ 0.90. AGFI is also above recommended level with the value of 0.901 . NFI has expected range of > 0.90 and its obtained value is 0.932 , which is also above the recommended level. The expected range of CFI is > 0.90 and its obtained value is 0.935 which is above the recommended level. TLI has expected range of $>0.90$ and in this model its obtained value is 0.925 , which is also above the recommended level.

The value of RMSEA below the range of 0.05 indicates goodness of fit. In this measurement model, obtained value is 0.040 and it is the indication of acceptable fit. In this model, the value of RMR is 0.048 and it is below the recommended level.

The results of confirmatory factor analysis show that model has acceptable fitness. Considering these results, it is quite evident that hypothesized six variables CFA model fits well with the sample data.

Overall Results of All Hypotheses

Table4.5.1. Overall results of all hypotheses

\begin{tabular}{|l|l|l|l|l|l|l|}
\hline Hypothesis & Structural Path & \multicolumn{2}{|c|}{$\beta$ value } & C.R & P-Value & $\begin{array}{l}\text { Significant/ } \\
\text { In Significant }\end{array}$ \\
\hline & & Estimate & Standard Error & & & \\
\hline H1 a & OPP<------ COIM & .482 & .269 & 2.732 & .003 & Significant \\
\hline H1 b & OPP<------ PNCC & .523 & .303 & 2.46 & $* * *$ & Significant \\
\hline H1 c & OPP<------ CUSS & .214 & .097 & 2.209 & $* * *$ & Significant \\
\hline H1 d & OPP<------RBT & .263 & .074 & 3.556 & $* * *$ & Significant \\
\hline H2 a & PSQ<------COIM & .700 & .256 & 2.732 & .006 & Significant \\
\hline H2 b & PSQ<------PNCC & .697 & .290 & 2.400 & $* * *$ & Significant \\
\hline H2 c & PSQ<------CUSS & .389 & .094 & 4.159 & $* * *$ & Significant \\
\hline H2 d & PSQ<------RBT & .095 & .071 & 2.159 & $* * *$ & Significant \\
\hline
\end{tabular}

\section{Effects of ISO 9001 on Organizational Performance}

The effect of ISO 9001 on the viability of the performance of the company's services is dictated by multiple linear regression analyzes. Regression analyzes were connected in light of summated sizes of dependent and independent variables (Psomas and Fotopoulos, 2010; Fotopoulos et al, 2009). Also, 
Waqar Ahmed "ISO 9001 transition and its impact on the organizational performance: Evidence from Service Industries of Pakistan"

on the premise of ISO 9001 objective summed scales, another planned summed scale is called "ISO 9001 effectiveness". Primary regression analysis investigation looks at the effect of the independent variables risk identification (RI), prevention of nonconformities (PNC), customer satisfaction (CS) and continuous improvement (CI) to "operational performance" dependent variable. Secondary regression analysis examination looks at the effect of independent variables risk identification (RI), prevention of nonconformities (PNC), customer satisfaction (CS) and continuous improvement (CI) to "product/service quality". Utilizing standardized residuals, suspicions required for every regression analysis and linearity particularly, Homoscedasticity, autonomy and ordinariness is tried. In view of the proposals of Hair, et al. (2005), particular tests were led for every hypothesis to look at infringement. As indicated by the outcomes, the presumptions are not disregarded. What's more, the multicollinearity among the independent variables in every regression analysis is checked and affirmed.

Considering the table 4.5.1 the regression analysis is factually significant. The evaluation of the model of regression, the outcomes demonstrate that "operational performance" and product/ service quality is specifically influenced by the "ISO 9001 effectiveness".

\section{Correlation Analysis}

Correlation analysis of all the variables studied in the research work are mentioned below in tabular form.

Table4.6.1. Correlation Matrix of study variables $(N=300)$

\begin{tabular}{|c|c|c|c|c|c|c|}
\hline Variables & CI & PC & CS & RI & OP & PQ \\
\hline \multirow{2}{*}{\multicolumn{7}{|c|}{$\begin{array}{l}\text { CI: Continuous } \\
\text { improvement }\end{array}$}} \\
\hline & & & & & & \\
\hline \multirow{2}{*}{$\begin{array}{l}\text { PC: Prevention of } \\
\text { nonconformities }\end{array}$} & & & & & & \\
\hline & $0.672^{* *}$ & $E$ & & & & \\
\hline \multirow{3}{*}{$\begin{array}{l}\text { CS: Customer } \\
\text { Satisfaction }\end{array}$} & & & & & & \\
\hline & $0.447^{* *}$ & $.512^{* *}$ & - & & & \\
\hline & & & & & & \\
\hline \multirow{2}{*}{$\begin{array}{ll}\text { RI: } & \text { Risk } \\
\text { identification } & \end{array}$} & $0.603^{* * *}$ & $0.624^{* * *}$ & $0.623^{* * *}$ & - & & \\
\hline & & & & & & \\
\hline \multirow{2}{*}{$\begin{array}{l}\text { OP: Operational } \\
\text { performance }\end{array}$} & $0516^{* * *}$ & $036^{* * *}$ & $0637^{* *}$ & $0566^{* *}$ & - & \\
\hline & & & & & & \\
\hline \multirow{2}{*}{$\begin{array}{l}\text { PQ: Product/service } \\
\text { Quality }\end{array}$} & & & & & & \\
\hline & $0.302^{* *}$ & $0.101^{* * *}$ & $0.255^{* * *}$ & $0.668^{* * *}$ & $0.577^{* * *}$ & - \\
\hline
\end{tabular}

Considering the Table 4.6.1 the correlation matrix coefficient between the measured variable showed by embracing different levels of items. A coefficient is viewed as substantial if the p quality is under 0.05 . There is a significant association between the independent and dependent variables as specified table 4.6.1. All coefficients of correlations are under 0.90. Bryman and Cramer (1997) proposed that "the Pearson $r$ between every pair of independent variables ought not to surpass 0.70 ; if not, the independent variables demonstrate a relationship to or more prominent than 0.70 can be recommended to present multicollinearity ".

The correlation matrix inter-scale of Table 4.6.1 demonstrates that the results of correlation analysis. As it can be seen from above table that all values of correlation are positive and significant at $95 \%$ confidence interval. The value of correlation between variable $\mathrm{CI}$ and $\mathrm{PC}$ is 0.672 that is positive and significant, similarly the value of correlation between the variable of CI and PC is 0.447 that is positive and significant. Similarly the value of correlation between CI and CS is 0.603 and between $\mathrm{CI}$ and RI it is 0.516 . Finally the correlation between $\mathrm{CI}$ and PQ is equal to 0.302 that is once again positive and significant.

If we closely observe table 4.6.1 we find out that the value of correlation between PC and CS is .512 that is positive and significant and Correlation between PC and RI is 0.624. Similarly the correlation 
Waqar Ahmed "ISO 9001 transition and its impact on the organizational performance: Evidence from Service Industries of Pakistan"

between PC \& OP and PC \& PQ is 0.36 and 0.101 both values are positive and significant at 95 percent level of significance. Furthermore the correlation between CS\&RI, CS \& OP, and CS \& PQ is $0.623,0.637$ and 0.255 respectively. Finally the correlation between OP\& RI, PQ \& RI and OP \& PQ are $0.565,0.668$ and 0.577 respectively.

\section{DISCUSSION}

\section{Theoretical Implication}

The outcomes of this work are in line and affirm the comparative investigation of Psomas et al. (2013) in the manufacturing sector. It contends for three inert variables delineating the ISO 9001 targets (continuous improvement, customer satisfaction focus and prevention of nonconformities) in view of which ISO 9001 viability is depicted. Researcher in this review/study decides ISO 9001 adequacy with four dormant elements delineating the ISO 9001 goals (continuous improvement, customer satisfaction focus, prevention of nonconformities and risk identification) (Pina and Selles, 2008) illustrate, like the present review, the association of ISO 9001 viability with the objectives of the standard, without, in any case, specifying the ISO 9001 effectiveness uncovered in the present review. (Augustyn and Pheby, 2000) additionally relate ISO 9001 effectiveness to the objectives of the standard and illustrate, correspondingly to the present review, that ISO 9001 positively effects on the performance of an organization. To the extent the significant execution measurements for an organization working in the service area are concerned, Zaramdini (2007) and Singh et al. (2006) decide, like the present study, dimensions identified with product/service quality, and operational performance. Enhanced internal operations and service quality accordingly of ISO 9001 implementation, as uncovered through the present review, are additionally apparent from the study of (McAdam and Canning, 2001), (Singh and Nahra, 2006), Lee et al. (2009) and (Wahid and Corner, 2009).

It will have real advantages for Quality Management Systems with less accentuation on documentation and new/strengthened methodologies like consideration of organizational Context and (relevant) Stakeholders, Risk Based thinking and Knowledge Management and ought to be a stage towards TQM.

In the researcher view the fundamental ISO 9001 modification objectives have been accomplished; a more Performance related standard, friendlier to parts like Services and Small and Medium Enterprises and not static but instead Risk Based. Furthermore, as expressed by Lee (2004), a few years back, yet at the same time particularly substantial today, organizations must be Agile (identify and react), Adaptable (imaginative and flexible) and Aligned (steadiness of purposes and values, straightforward, bona fide, dependable and working forward long haul common advantageous Stakeholders connections).

\section{Practical Implication}

The success of implementing ISO 9000 certification would be increased (operational and business performance) if it is well planned and implemented when the philosophical quality aspects of the organisations are coupled with employee training, periodic audits, corrective action and commitment at all levels of the organisations.

By defining ISO 9001 effectiveness based on its objectives, managers may be aware of what to improve to increase the standard's effectiveness and therefore directly improve service organization performance in terms of quality and operative results and indirectly in terms of financial results.

\section{ISO 9001 Effectiveness and Operational Performance}

The results showed that the majority of respondents felt that it increases the number of customers, improved customer satisfaction and increased revenues from the software industry. The finding that the ISO has contributed positively in terms of customer satisfaction has been reinforced by evidence detailing compliments increase and a reduction in customer complaints.

\section{ISO 9001 effectiveness and product / service quality}

The results show that the majority of respondents felt that the provision of work instructions, training and a supportive work environment ensures people to perform tasks effectively, and the provision of data to determine the performance of business processes, services to improve organizational performance and customer satisfaction. 
Waqar Ahmed "ISO 9001 transition and its impact on the organizational performance: Evidence from Service Industries of Pakistan"

\section{Research Limitation and Suggestions for Further Studies}

The study aimed to evaluate the effectiveness of ISO 9001 organizational performance by assessing whether ISO certification can make a positive impact on operational performance and product / service quality. Future studies should be conducted with special emphasis on respondents customers because it is noted that many specific performance measures are related to the quality of services must take into account the opinions held by clients themselves the quality of service they receive. It would also be important to include a lot more stakeholders such as suppliers in determining how organizational performance can be affected by the certification ISO 9001, future studies may use other tools such as major focus on group discussions to provide a deeper understanding of the subject. Finally, this study was directed in only Software industries of Pakistan future researcher may conduct this research in any other sector of Pakistan like manufacturing, retailing etc. Current research work focused private and government software industries of Pakistan future researcher may compare the ISO effectiveness on organizational performance in developed and developing countries.

\section{REFERENCES}

[1] Evangelos L. Psomas Angelos Pantouvakis Dimitrios P. Kafetzopoulos, (2013),"The impact of ISO 9001effectiveness on the performance of service companies", Managing Service Quality: An International Journal, Vol. 23 Iss 2 pp. 149 - 164

[2] Evangelos L. Psomas, Christos V. Fotopoulos, Dimitrios P. Kafetzopoulos, (2010),"Critical factors for effective implementation of ISO 9001 in SME service companies", Managing Service Quality: An International Journal, Vol. 20 Iss 5 pp. 440-457

[3] Paulo Sampaio, Pedro Saraiva, António Guimarães Rodrigues, (2009),"ISO 9001 certification research: questions, answers and approaches", International Journal of Quality \&amp; Reliability Management, Vol.26 Iss 1 pp. 38-58

[4] Borut Rusjan, Milena Ali, (2010),"Capitalizing on ISO 9001 benefits for strategic results", International Journal of Quality \&amp; Reliability Management, Vol. 27 Iss 7 pp. 756-778

[5] Beattie, K. R., \& Sohal, A. S. (1999). Implementing ISO 9001: A study of its benefits among Australian organizations. Total Quality Management, 10(1), 95- 106.

[6] Sharma, D. (n.d.). The association between ISO 9001 certification and financial performance. The International Journal of Accounting, 40(2005), 151- 172

[7] Lima, M., Resende, M., \& Hasenclever, L. (n.d.). Quality certification and performance of Brazilian firms: An empirical study. Int. J. Production Economics, 66(2000), 143-147.

[8] Charles J. Corbett, María J. Montes-Sancho, David A. Kirsch, (2005) The Financial Impact of ISO 9000 Certification in the United States: An Empirical Analysis. Management Science 51(7):1046-1059.

[9] Priede, J. (n.d.). Implementation of Quality Management System ISO 9001 in the World and its Strategic Necessity. Procedia - Social and Behavioral Sciences, 58(2012), 1466 - 1475.

[10] Mei Feng Mile Terziovski Danny Samson, (2007),"Relationship of ISO 9001:2000 quality system certification with operational and business performance", Journal of Manufacturing Technology Management, Vol. 19 Iss 1 pp. 22 - 37

[11] Evangelos L. Psomas Angelos Pantouvakis Dimitrios P. Kafetzopoulos, (2013),"The impact of ISO 9001 effectiveness on the performance of service companies", Managing Service Quality: An International Journal, Vol. 23 Iss 2 pp. 149 - 164

[12] Ndirangu P. W., (2011): The strategic value of ISO certification among state owned enterprises in Kenya: Unpublished MBA Project: University of Nairobi

[13] Terlaak, A., and King A., 2006. The effect of certification with the ISO 9001 quality management standard: A signaling approach. Journal of Economic Behavior and Organization 60: 579-602.

[14] Paulo Sampaio Pedro Saraiva Antonio Guimaraes Rodrigues, (2009),"ISO 9001 certification research: questions, answers and approaches", International Journal of Quality \& Reliability Management, Vol. 26 Iss 1 pp. $38-58$ 
Waqar Ahmed "ISO 9001 transition and its impact on the organizational performance: Evidence from Service Industries of Pakistan"

[15] Evangelos L. Psomas Christos V. Fotopoulos Dimitrios P. Kafetzopoulos, (2010),"Critical factors for effective implementation of ISO 9001 in SME service companies", Managing Service Quality: An International Journal, Vol. 20 Iss 5 pp. 440 - 457

[16] Peter K.C. Lee W.M. To Billy T.W. Yu, (2009),"The implementation and performance outcomes of ISO 9000 in service organizations", International Journal of Quality \& Reliability Management, Vol. 26 Iss 7 pp. 646 -662

[17] S.L. Tang C.W. Kam, (1999),"A survey of ISO 9001 implementation in engineering consultancies in Hong Kong", International Journal of Quality \& Reliability Management, Vol. 16 Iss 6 pp. $562-574$

[18] Marcjanna M. AugustynJohn D. Pheby, (2000),"ISO 9000 and performance of small tourism enterprises: a focus on Westons Cider Company", Managing Service Quality: An International Journal, Vol. 10 Iss 6 pp. $374-388$

[19] Prakash J. Singh Mei Feng Alan Smith, (2006),"ISO 9000 series of standards: comparison of manufacturing and service organisations", International Journal of Quality \& Reliability Management, Vol. 23 Iss 2 pp. 122- 142

[20] Prakash J. Singh Peter Mansour-Nahra, (2006),"ISO 9000 in the public sector: a successful case from Australia", The TQM Magazine, Vol. 18 Iss 2 pp. 131 - 142

\section{AUTHOR'S BIOGRAPHY}

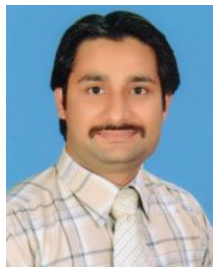

Waqar Ahmed has completed his MS in Project Management from COMSATS, Pakistan with 1-year research phase at COMSATS Institute of Technology, Pakistan. $\mathrm{He}$ is Technology Enthusiast with over 8 years experience in Process Management, Team Management, System Analysis, Design and Development of products related to ECommerce, Payments, Retail, Financial, Security, Smart Card, Biometric and Production based Systems.

His research interests include quality management systems, quality assurance and ISO effectiveness process areas. 